tiatherogenic effect of captopril in the Watanabe heritable hyperlipidemic rabbit. Hypertension 1990;15:327-31.

13. Lüscher TF, Wenzel RR, Moreau P, Takase H. Vascular protective effects of ACE inhibitors and calcium antagonists: theoretical basis for a combination therapy in hypertension and other cardiovascular diseases. Cardiovasc Drugs Ther 1995; Suppl 3: 509-23.

14. Chobanian AV, Bakris GL, Black HR, et al. The Seventh
Report of the Joint National Committee on Prevention, Detection, Evaluation, and Treatment of High Blood Pressure: the JNC 7 report. JAMA 2003;289:2560-72. [Erratum, JAMA 2003; 290:197.]

15. Beckett NS, Peters R, Fletcher AE, et al. Treatment of hypertension in patients 80 years of age or older. N Engl J Med 2008; 358:1887-98.

Copyright (c) 2008 Massachusetts Medical Society.

\title{
Chronic Hepatitis B - New Goals, New Treatment
}

\author{
Ching-Lung Lai, M.D., and Man-Fung Yuen, M.D.
}

The hepatitis B virus (HBV) causes chronic infection in approximately 400 million people in the world. Most carriers of chronic HBV, including Asians, Africans, and a proportion of persons in Mediterranean countries, acquire the infection at birth or within the first 1 to 2 years after birth. ${ }^{1}$ It is estimated that $50 \%$ of male carriers and $14 \%$ of female carriers will eventually die of the complications of cirrhosis and hepatocellular carcinoma. $^{2}$

The criteria and end points for the treatment of chronic HBV infection should be reevaluated in light of three important recent findings. First, more than $70 \%$ of patients with complications of cirrhosis and hepatocellular carcinoma are negative for the hepatitis B e antigen (HBeAg). ${ }^{3}$ Therefore, although the disease may become quiescent in some patients after HBeAg seroconversion, the disease can progress, and most disease-related deaths occur in these patients. Even with clearance of the hepatitis B surface antigen (HBsAg), there is no decrease in the risk of hepatocellular carcinoma if the HBsAg is lost in patients after the age of 50 years. ${ }^{4}$

Second, an elevated HBV DNA level of more than 2000 IU per milliliter $\left(10^{4}\right.$ copies per milliliter) is a strong independent predictor of the risk of complications of cirrhosis and hepatocellular carcinoma., ${ }^{5,6}$ Prolonged, effective suppression of HBV DNA has been shown to decrease the risk of the development of cirrhosis and hepatocellular carcinoma. ${ }^{7,8}$

Finally, as is the case in chronic hepatitis C infection, patients with chronic HBV infection who have alanine aminotransferase levels that are near the upper limit of the normal range are at a significantly higher risk for complications of cirrhosis and hepatocellular carcinoma than pa- tients with alanine aminotransferase levels that are less than half the upper limit of the normal range. ${ }^{3}$ The highest risk of complications of cirrhosis and hepatocellular carcinoma occurs in patients with alanine aminotransferase levels that are one to two times the upper limit of the normal range.

The implications for the treatment of chronic HBV infection are that, other than the traditional end point of HBeAg seroconversion alone, a more important aim is the sustained suppression of HBV DNA to very low levels, preferably to below the detection limit of sensitive polymerasechain-reaction (PCR) assays. ${ }^{1}$ The alanine aminotransferase level should also ideally be lower than half the upper limit of the normal range.

The first licensed agent for the treatment of chronic HBV infection was the conventional form of interferon alfa, which acts mainly through immunomodulation and has the advantage of being given over a fixed period of time, although this is partly because of its often severe side effects. However, the majority of patients still have levels of HBV DNA that are detectable by means of PCR assays after treatment, and most studies show no decrease in the occurrence of hepatocellular carcinoma on long-term follow-up. ${ }^{9,10}$ The short-term efficacy of pegylated interferon (peginterferon), licensed in 2005, is almost identical to that of conventional interferon. Data on its long-term effects on the development of cirrhosis and hepatocellular carcinoma have not yet been published.

Lamivudine, a nucleoside analogue, was licensed in 1998. Nucleoside and nucleotide analogues suppress HBV replication through inhibition of the reverse-transcriptase and DNA polymerase activities. During the past decade, four other nucleo- 
side and nucleotide analogues have been licensed: adefovir (in 2002), entecavir (in 2005), telbivudine (in 2006), and, most recently, tenofovir disoproxil fumarate (DF) (in 2008).

In this issue of the Journal, Marcellin et al. ${ }^{11}$ report on two studies comparing the antiviral efficacy of tenofovir DF with that of adefovir dipivoxil in both HBeAg-negative and HBeAg-positive patients; $18 \%$ of the HBeAg-negative patients had received lamivudine previously. At week 48, tenofovir DF was superior to adefovir dipivoxil in achieving the primary end point, defined as the combination of an HBV DNA level of less than 400 copies per milliliter (69 IU per milliliter) and histologic improvement $(\mathrm{P}<0.001)$. A total of $93 \%$ of the HBeAg-negative patients and $76 \%$ of the HBeAg-positive patients who received tenofovir DF (the intention-to-treat population) had an HBV DNA level of less than 400 copies per milliliter by week 48. The choice of this HBV DNA level as the primary end-point threshold was dictated by the detection limit of the sequencing assay used for resistance surveillance. However, the detection limit of the PCR assay used for quantification of HBV DNA in the studies was 169 copies per milliliter (29 IU per milliliter). This end-point threshold for HBV DNA would have been a better choice, because lower levels of HBV DNA measurement would allow earlier detection of viral rebound ${ }^{12}$ and because the modern treatment end points aim at suppressing HBV DNA to as low a level as possible. ${ }^{1}$

Two of the most encouraging aspects of tenofovir DF in the studies reported by Marcellin et al. are its efficacy in patients with a lamivudineresistant virus and the absence of resistant mutations up to week 48. A longer treatment period is of course required to determine the incidence of tenofovir DF resistance. The relative efficacy and resistance rates of the approved drugs are listed in Table 1.

The most obvious niche for tenofovir DF is in

\begin{tabular}{|c|c|c|c|c|c|c|}
\hline \multirow[t]{2}{*}{ Variable } & $\begin{array}{l}\text { Pegylated } \\
\text { Interferon }\end{array}$ & Lamivudine & $\begin{array}{l}\text { Adefovir } \\
\text { Dipivoxil }\end{array}$ & Entecavir & Telbivudine & Tenofovir DF \\
\hline & \multicolumn{6}{|c|}{ percent of patients } \\
\hline \multicolumn{7}{|c|}{ HBeAg-positive patients } \\
\hline \multicolumn{7}{|c|}{ Undetectable HBV DNA by PCR ${ }^{\dagger}$} \\
\hline $1 \mathrm{yr}$ & 25 & 36 & 21 & 67 & 60 & 76 \\
\hline $2 \mathrm{yr}$ & NA & NA & 40 & 80 & 56 & NA \\
\hline $3 \mathrm{yr}$ & NA & NA & 48 & 82 & NA & NA \\
\hline \multicolumn{7}{|c|}{ Resistance } \\
\hline $1 \mathrm{yr}$ & 0 & 24 & 0 & $<1$ & 4 & 0 \\
\hline $2 \mathrm{yr}$ & - & 42 & NA & $<1$ & 25 & NA \\
\hline $5 \mathrm{yr}$ & - & 76 & 20 & 1 & NA & NA \\
\hline \multicolumn{7}{|c|}{ HBeAg-negative patients } \\
\hline \multicolumn{7}{|c|}{ Undetectable HBV DNA by PCR '† } \\
\hline $1 \mathrm{yr}$ & 63 & 72 & 63 & 90 & 88 & 93 \\
\hline $2 \mathrm{yr}$ & NA & NA & 71 & 94 & 82 & NA \\
\hline $3 \mathrm{yr}$ & NA & NA & 79 & NA & NA & NA \\
\hline \multicolumn{7}{|c|}{ Resistance } \\
\hline $1 \mathrm{yr}$ & 0 & 21 & 0 & $<1$ & 3 & 0 \\
\hline $2 \mathrm{yr}$ & - & 35 & 3 & $<1$ & 11 & NA \\
\hline $5 \mathrm{yr}$ & - & NA & 29 & 1 & NA & NA \\
\hline
\end{tabular}

* Data are from Yuen et al., ${ }^{13}$ Marcellin et al., ${ }^{11,14}$ Hadziyannis et al., ${ }^{15}$ Tenney et al., ${ }^{16}$ and Liaw et al. ${ }^{17}$ HBeAg denotes hepatitis B e antigen, HBV hepatitis B virus, NA not available, and PCR polymerase chain reaction.

$\uparrow$ The lower limit of detection varied from 40 to less than $200 \mathrm{IU}$ per milliliter ( 200 to $<1000$ copies per milliliter). 
the treatment of patients with lamivudine-resistant HBV. Tenofovir DF is superior to adefovir dipivoxil and entecavir in these patients, and it has a much lower renal toxicity than adefovir dipivoxil. ${ }^{18}$ An even greater prospect is its potential use as a first-line drug in patients who have not received treatment; these patients compose the great majority of the population of persons with chronic HBV infection in the world. One of the besetting problems with nucleoside and nucleotide analogues is the development of resistance with long-term use. Early suppression of HBV DNA (e.g., to <40 IU per milliliter [200 copies per milliliter] by week 24) has proved to be associated with low rates of resistance development. ${ }^{13}$ Although we must await further studies to determine the long-term resistance to tenofovir $\mathrm{DF}$, it is encouraging to note that $86 \%$ of $\mathrm{HBeAg}$ negative patients and $50 \%$ of HBeAg-positive patients had HBV DNA levels that were less than 400 copies per milliliter at week 24 . The resistance rate for adefovir dipivoxil after 5 years of treatment is $20 \%$ among HBeAg-positive patients and $29 \%$ among $\mathrm{HBeAg}$-negative patients. ${ }^{14,15}$ It is to be expected that resistance to tenofovir DF would be lower because of its greater efficacy in viral suppression.

Finally, what is the possible future role of tenofovir DF in combination therapy? In HBeAgnegative patients, long-term therapy with nucleoside and nucleotide analogues is the standard practice. However, in HBeAg-positive patients, most treatment guidelines suggest that therapy may be discontinued after a stable HBeAg seroconversion, preferably with levels of HBV DNA that are undetectable by means of PCR assays. Nevertheless, at least one study in HBeAg-positive patients shows that even with a relatively weak agent such as lamivudine, continuing drug treatment after HBeAg seroconversion results in better sustained suppression of HBV DNA and fewer alanine aminotransferase flares than discontinuing the treatment. ${ }^{19}$ Long-term therapy in both HBeAg-positive and HBeAg-negative patients with sustained viral suppression will most likely be the trend in the future. The problem of resistance will become a major concern. Although most studies with combination therapy show no additive antiviral effects, combination therapy has resulted in a reduction of resistance development. The ideal combination may be a nucleoside analogue such as lamivudine or telbivudine with a nucleo- tide analogue such as adefovir dipivoxil or tenofovir DF; in this combination therapy, one group of agents will remain sensitive to the resistant mutant viruses of the other group. However, if the long-term resistance to tenofovir DF turns out to be very low, similar to the $1.2 \%$ resistance rate after 5 years of treatment with entecavir among patients who have not received treatment previously, ${ }^{16}$ long-term monotherapy with tenofovir DF or entecavir is another possible option.

Dr. Lai reports receiving consulting and lecture fees from Bristol-Myers Squibb and lecture fees from Novartis, and Dr. Yuen, consulting fees from Bristol-Myers Squibb, GlaxoSmithKline, and Pfizer and lecture fees from Novartis, Bristol-Myers Squibb, and Roche. Both authors were invited by Gilead Sciences to an "HBV Global Summit" meeting, for which they did not receive any fees. No other potential conflict of interest relevant to this article was reported.

From the Department of Medicine, University of Hong Kong, Hong Kong.

1. Lai CL, Yuen MF. The natural history and treatment of chronic hepatitis B: a critical evaluation of standard treatment criteria and end points. Ann Intern Med 2007;147:58-61.

2. Beasley PR. Hepatitis B virus as the etiologic agent in hepatocellular carcinoma - epidemiologic considerations. Hepatology 1982;2:Suppl:21S-26S.

3. Yuen MF, Yuan HJ, Wong DK, et al. Prognostic determinants for chronic hepatitis B in Asians: therapeutic implications. Gut 2005;54:1610-4.

4. Yuen MF, Wong DKH, Fung J, et al. HBsAg seroclearance in chronic hepatitis B in Asian patients: replicative level and risk of hepatocellular carcinoma. Gastroenterology 2008;135:1192-9.

5. Chen CJ, Yang HI, Su J, et al. Risk of hepatocellular carcinoma across a biological gradient of serum hepatitis B virus DNA level. JAMA 2006;295:65-73.

6. Iloeje UH, Yang HI, Su J, et al. Predicting cirrhosis risk based on the level of circulating hepatitis B viral load. Gastroenterology 2006;130:678-86.

7. Liaw Y-F, Sung JJY, Chow WC, et al. Lamivudine for patients with chronic hepatitis B and advanced liver disease. N Engl J Med 2004;351:1521-31.

8. Yuen MF, Seto WK, Chow DHF, et al. Long-term lamivudine therapy reduces the risk of long-term complications of chronic hepatitis B infection even in patients without advanced disease. Antivir Ther 2007;12:1295-303.

9. Yuen MF, Hui CK, Cheng CC, Wu CH, Lai YP, Lai CL. Longterm follow-up of interferon alpha treatment in Chinese patients with chronic hepatitis B infection: the effect on hepatitis B e antigen seroconversion and the development of cirrhosis-related complications. Hepatology 2001;34:139-45.

10. International Interferon- $\alpha$ Hepatocellular Carcinoma Study Group. Effect of interferon- $\alpha$ on progression of cirrhosis to hepatocellular carcinoma: a retrospective cohort study. Lancet 1998:351:1535-9.

11. Marcellin P, Heathcote EJ, Buti M, et al. Tenofovir disoproxil fumarate versus adefovir dipivoxil for chronic hepatitis B. N Engl J Med 2008;359:2442-55.

12. Locarnini S, Hatzakis A, Heathcote J, et al. Management of antiviral resistance in patients with chronic hepatitis B. Antivir Ther 2004;9:679-93.

13. Yuen MF, Sablon E, Hui CK, Yuan HJ, Decraemer H, Lai CL. Factors associated with hepatitis B virus DNA breakthrough in patients receiving prolonged lamivudine therapy. Hepatology 2001;34:785-91. 
14. Marcellin P, Chang TT, Lim SG, et al. Long-term efficacy and safety of adefovir dipivoxil for the treatment of hepatitis B e antigen-positive chronic hepatitis B. Hepatology 2008;48:750-8. 15. Hadziyannis SJ, Tassopoulos NC, Heathcote EJ, et al. Longterm therapy with adefovir dipivoxil for HBeAg-negative chronic hepatitis B for up to 5 years. Gastroenterology 2006;131:174351.

16. Tenney DJ, Rose RE, Bladick CJ, et al. Long-term monitoring shows hepatitis B virus resistance to entecavir in nucleosidenaïve patients is rare through 5 years of therapy. Hepatology (in press).

17. Liaw Y-F, Gane E, Leung N, et al. 2-Year GLOBE trial results: telbivudine is superior to lamivudine in patients with chronic hepatitis B. Gastroenterology (in press).

18. van Bömmel F, Zöllner B, Sarrazin C, et al. Tenofovir for patients with lamivudine-resistant hepatitis B virus (HBV) infection and high HBV DNA level during adefovir therapy. Hepatology 2006;44:318-25.

19. Fung J, Lai CL, Tanaka Y, et al. The duration of lamivudine therapy for chronic hepatitis B: cessation versus continuation of treatment after HBeAg seroconversion. Am J Gastroenterol (in press).

Copyright @ 2008 Massachusetts Medical Society.

FULL TEXT OF ALL JOURNAL ARTICLES ON THE WORLD WIDE WEB

Access to the complete text of the Journal on the Internet is free to all subscribers. To use this Web site, subscribers should go to the Journal's home page (www.nejm.org) and register by entering their names and subscriber numbers as they appear on their mailing labels. After this one-time registration, subscribers can use their passwords to log on for electronic access to the entire Journal from any computer that is connected to the Internet. Features include a library of all issues since January 1993 and abstracts since January 1975, a full-text search capacity, and a personal archive for saving articles and search results of interest. All articles can be printed in a format that is virtually identical to that of the typeset pages. Beginning 6 months after publication, the full text of all Original Articles and Special Articles is available free to nonsubscribers. 